\title{
Benthic communities and genetic structure of caddisfly Stenopsyche marmorata along a mountain stream fragmented by slit and unslit sabo dams
}

\author{
K. Nukazawa ${ }^{1}$, S. Kazama ${ }^{1}$, K. Watanabe ${ }^{2}$ \& J. Kang ${ }^{3}$ \\ ${ }^{I}$ Graduate School of Engineering, Tohoku University, Japan \\ ${ }^{2}$ Leibniz-Institute of Freshwater Ecology and Inland Fisheries (IGB), \\ Germany \\ ${ }^{3}$ Graduate School of Environmental Studies, Tohoku University, Japan
}

\begin{abstract}
In order to assess the impacts of sabo dam (check dam) construction, species diversity of benthic faunal communities and genetic diversity of caddisfly Stenopsyche marmorata were investigated using microsatellite analysis along the Oisawa River, Japan. The Oisawa River is fragmented by two slit sabo dams and one unslit sabo dam. Over the slit dams, Shannon-Weiner diversity indices and number of taxa ranged from 0.90 to 1.02 and 13 to 15 respectively in the upstream region, and also from 0.98 to 1.18 and 13 to 20 respectively in the downstream region. Through microsatellite analysis of $S$. marmorata, we found two selective alleles, which show clear genetic differentiation among three upstream sites and four downstream sites in the study area. Longitudinal change of mean heterozigosities $\mathrm{H}_{\mathrm{o}}$ showed a decreasing pattern of genetic diversity in the downstream site $(=0.486-0.678)$, and it showed the highest diversity at the highest upstream site, which receives no effect of the unslit dam. Differences of community's species compositions between sites were correlated to geographical distances whereas genetic distances between sites were not correlated to geographical distances, suggesting that species compositions of the communities were determined through the process of species adaptation to the local environment. We concluded that increments of species diversity at the inlet reaches of the slit dam were caused by the recovery of habitats, and by the continuousness of the stream which allows the flowing of particulate organic
\end{abstract}


matters and sediments to the downstream area. In part of some loci, genetic selection might occur by the different velocities caused by sabo dam constructions, because $S$ marmorata (filter-feeder) has the habit of constructing nets to filter and collect fine particulate organic matter (FPOM) from water flow. Keywords: macroinvertebrate, species diversity, genetic diversity, Stenopsyche marmorata, microsatellite DNA, check dam, small scale analysis.

\section{Introduction}

The unslit sabo dam (or check dam) stores sedimentation from the upstream and makes the river gradient lower. As a result, the dam reduces erosion, excessive sediment accumulation at reservoir located in the downstream, and landslides. However, it also has some negative effects because the river stream is fragmented by an unslit sabo dam causing sedimentation level in the upstream reach becomes fairly homogenous, while river bed in the downstream reach is degradated. Up to today, although many concerns are on the impact of the reservoir dams to river ecosystems (e.g. Gillenwater et al. [1], Watanabe and Omura [2]), impacts of sabo facility have not been well studied.

Many of sabo dams are located in the mountain streams in Japan. In such high velocity streams, many of aquatic insects do not tend to swim but attach to the stony or rocky substrate of the river bed and construct the nest (Attachers), crawl on various substrates (Crawlers), and burrow into gaps of the river bed (Burrowers) (Ohgushi [3], Takemon [4]). Accordingly, the topographical change of the river section caused by the sabo facility might trigger significant impacts to aquatic insects living in the mountain streams. Nunokawa and Kikuchi [5] evaluated longitudinal change of macroinvertebrate density from sabo dam to downstream and Kitamura and Ishimatsu [6] surveyed drift; the characteristics of aquatic insects flowing to downstream in a mountain stream with sabo facilities.

Recently, many of unslit sabo dams are reconstructed to slit sabo dams (fig. 1). Because slit sabo dam sustains continuousness of river stream, sediment and aquatic organisms including macroinvertebrate in upstream reach can flow to

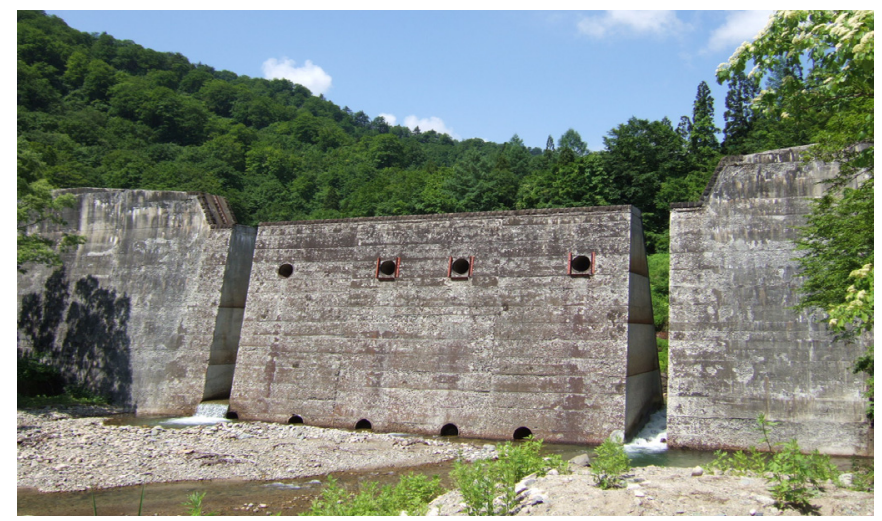

Figure 1: $\quad$ Slit type sabo dam. 
downstream as similar to the natural condition. Therefore, evaluation of benthic macroinvertebrate along river fragmented by sabo facility is important for deriving some effect of it to river ecosystem.

For these purposes, species diversity (Shannon-Weiner diversity index and benthic community) and genetic structure (Heterozigosity, allele frequency and Slatkin's genetic distance) of caddisfly Stenopsyche marmorata were investigated in a mountain stream.

\section{Method}

\subsection{Study area}

Oisawa River is a mountain stream ranging from 450 to $700 \mathrm{~m}$ in altitude in Yamagata prefecture in Japan (fig. 2). Air temperature ranges from $-15^{\circ} \mathrm{C}$ in winter to $32^{\circ} \mathrm{C}$ in summer and annual rainfall is around $2,500 \mathrm{~mm}$ in the study area. The river is fragmented by two slit dams and one unslit dam. Some residences are located but only close to river mouth of the Oisawa River, the rest of the river is surrounded by a canopy throughout the study area. The Oisawa Dai-ni dam, Dai-san dam and Dai-yon dam were completed in 1968, 1978 and 1984, respectively. Dai-ni dam and of Dai-san dam were slitted on 2004 and 2007, respectively. Study sites (observation points) were selected at inlet and outlet reaches of the unslit sabo dam (st.2 and st.3), the slit sabo dams (st.4 and st.5, st.6 and st.7, respectively) and the two sites which were hardly affected by unslit (st.1) and slit dam (st.8). The site st.1 was located at approximately $300 \mathrm{~m}$ upstream from Dai-yon dam and st.8 was located approximately $1,000 \mathrm{~m}$ downstream from Dai-ni dam.

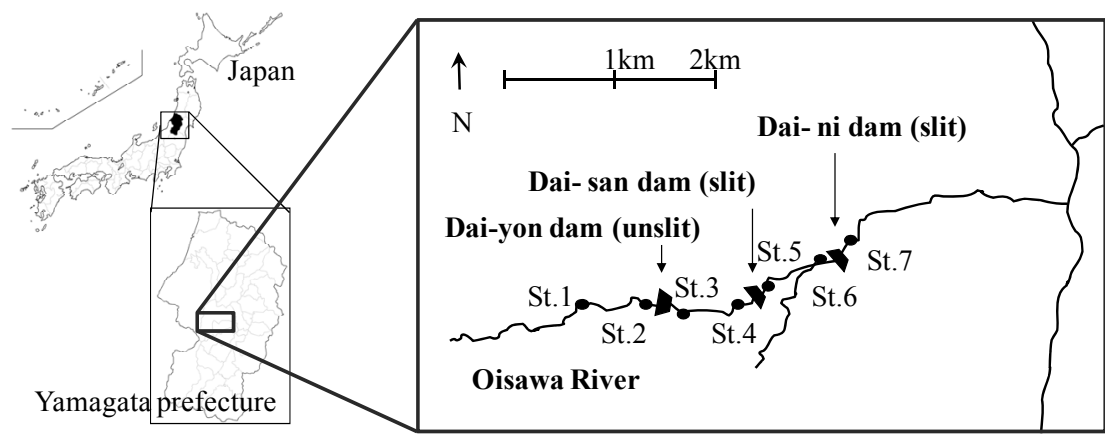

Figure 2: $\quad$ Study area Oisawa river.

\subsection{Selected species and survey method}

Caddisfly Stenopsyche marmorata (S. marmorata) is distributed from upper to down streams throughout Japan. In larval stage, $S$. marmorata constructs fixed type nest consist of secreted silk and feeds particle organic matter by filtering through the nest [3]. The average size of $S$. marmorata is around $40 \mathrm{~mm}$. $S$. 
marmorata flows to downstream in larval stage and run up to upstream by flying in adult stage (Nishimura [7]). This process is called colonization cycle (Muller [8]). Flight distance of adult individual is reported as approximately from 2.5 to $3.1 \mathrm{~km}$ [7]. Therefore, river traversing structures such as sabo dam can interrupt such migrations.

Benthic communities were collected by quantitative sampling using a net attached to a quadrat $(30 \mathrm{~cm} \times 30 \mathrm{~cm}$, mesh size is $250 \mu \mathrm{m})$ at eight stations from April to July 2009. Individuals of $S$. marmorata were collected up to 20 in numbers at each station except st. 8 on November 2008 due to absence of habitat at that time. Quantitative samplings were conducted in three randomly selected places per one site where the reach is from 20 to $30 \mathrm{~m}$. The total of them regard as total population density $\mathrm{N}\left(1 / \mathrm{m}^{2}\right)$. Then, benthic invertebrates were dipped into $99.5 \%$ ethanol and stored in an isothermal room. Invertebrates were identified accurately as possible using a stereomicroscope (150x) according to Kawai [9], and classified to different levels as species, genus and family. These were combined as taxa.

The representative velocities at each site were calculated by averaging ten measurements recorded by an electromagnetic velocity meter.

\subsection{Species diversity}

Species diversities of intra-population were evaluated by taxa $S$ and ShannonWeiner's diversity index $H^{\prime}$. Generally, if numbers of species are abundant, the species diversity index shows high value. However, species diversity can decrease accordingly by the absence of variety of species (e.g. there are dominant species and hence not other species) even if numbers of species are abundant. Species diversity has two concepts; abundant and equality. Using eqn (1) which account the effects of both concepts, Shannon-Weiner's diversity index $H^{\prime}$ was calculated (Shannon [10]).

$$
H^{\prime}=-\sum\left(\frac{x_{i}}{N}\right) \log \left(\frac{x_{i}}{N}\right)
$$

Diversities of inter-population were evaluated using Pianka's similarity index $\alpha$ (eqn (2)) ranging from 0 to 1 (Pianka [11]). Value 1 means two populations are identical.

$$
\begin{gathered}
\alpha=\sum \frac{p_{A i} \cdot p_{B i}}{\sqrt{\sum p_{A i}^{2} \cdot \sum p_{B i}^{2}}} \\
p_{A i}=\frac{n_{A i}}{N_{A}} \quad p_{B i}=\frac{n_{B i}}{N_{B}}
\end{gathered}
$$

where $N_{A}$ and $N_{B} 1\left(/ \mathrm{m}^{2}\right)$ are population densities at station $\mathrm{A}$ and $\mathrm{B}, n_{A i}$ and $n_{B i}$ $\left(1 / \mathrm{m}^{2}\right)$ are population densities of taxa $\mathrm{i}$ at station $\mathrm{A}$ and $\mathrm{B}$. Then, differences between communities $\theta(=1-\alpha)$ ranging from 0 to 1 (value 0 means two populations are identical) were evaluated. 


\subsection{Microsatellite analysis}

Microsatellite analysis is a method to detect DNA polymorphism amplifying short tandem repeat (microsatellite, STR or SSR) in sequence of bases. Generally, microsatellite has higher mutational rate compared to other DNA region, and thus genetic variant between individuals of intraspecies can be detected more easily. Accordingly, genetic differentiation can be evaluated with high accuracy for the study area with small scale area.

At first, tissue within body of $S$. marmorata was harvested using a pair of tweezers and dipped into $0.5 \mathrm{~m} l \mathrm{HMW}$ buffer $(10 \mathrm{mM}$ Tris- $\mathrm{HCl}, 150 \mathrm{mM} \mathrm{NaCl}$ and $10 \mathrm{mM}$ EDTA-NaOH (pH8.0)) within $1.5 \mathrm{~m} l$ test tube. Then, the tissue was mashed by using stirring pestle, dipped into $5 \mu l$ SDS (Sodium Dodecyl Sulfate) with $5 \mu l$ Proteinase $\mathrm{K}$ solution $(10 \mathrm{mg} / \mathrm{m} l)$, and incubated on $55^{\circ} \mathrm{C}$ for 30 minutes. Afterward, Centrifugal separation $\left(10,000 \mathrm{G}, 20^{\circ} \mathrm{C}, 10\right.$ minutes $)$ with phenol saturated by TE (10mM Tris-HSl (pH8.0), 10mM EDTA-NaOH (pH8.0)) and CIA (Chloroform 96\%, isoamyl alcohol 4\%) was carried out, finally, DNA pellet was obtained by precipitating within ethanol. The pellet was dissolved with $100 \mu l \mathrm{TE}$ as 'sample DNA' and stored on the condition $-20^{\circ} \mathrm{C}$.

In this study, 10 fluorescently-labeled primer pairs of $S$. marmorata developed by Yaegashi et al [12] were used for PCR. The primers steno03, steno07, steno08 and steno10 which PCR was successfully conducted in the primer pairs were used for analysis. Reagents of PCR are $1 \mu l$ TaKaRa Taq TM (5units $/ \mu l$ ), $2 \mu l 10 *$ PCR Buffer $\left(\mathrm{Mg}^{2+}\right.$ free), $2.4 \mu l 25 \mathrm{mM} \mathrm{MgCl} 2,1.6 \mu l$ dNTP Mixture $(2.5 \mathrm{mM}$ each), $5 \mu l$ sterilized water and $1.6 \mu l 10 \%$ Tween 20 . The set of reagents and sample DNA were blended with $1 \mu l$ steno03 $(0.25 \mathrm{mM})$ and steno07 $(0.25 \mathrm{mM})$ for $\mathrm{F}$ and $\mathrm{R}$, respectively, and $0.1 \mu l$ steno $08(0.1 \mathrm{mM})$ and $1 \mu l$ steno 10 $(1 \mathrm{mM})$ for F and R, respectively. PCR was conducted using this mixed solution. PCR process is cycle of 35 times of thermal denaturation $\left(94^{\circ} \mathrm{C}, 30 \mathrm{sec}\right)$, annealing $\left(45^{\circ} \mathrm{C}, 30 \mathrm{sec}\right)$ and extension $\left(72^{\circ} \mathrm{C}, 2 \mathrm{~min}\right)$, by using a thermal cycler (TaKaRa). After successful amplifying, DNA fragment sizes were analyzed by capillary electrophoresis by using ABI PRISM ${ }^{\circledR 3}$.1.2 (Applied Biosystems).

\subsection{Genetic diversity}

Genetic diversity can be separated into 1) mutation of gene between intraspecies individuals (intra-population), and 2) mutation of genetic structure between populations (inter-population). Allele frequency and mean heterozigosity $\mathrm{H}_{\mathrm{o}}$ $\left(=1 / \mathrm{n} \sum \mathrm{N}_{\text {het }} / \mathrm{N}\right.$ : where $\mathrm{n}$ is number of locus $(=4), \mathrm{N}_{\text {het }}$ is number of individual detected as heterozygote and $\mathrm{N}$ is number of individual used for genetic analysis) of each locus were evaluated. Existence or nonexistence of deviation from Hardy-Weinberg Equilibrium (HWE) was tested. Slatkin's genetic distance D which represents genetic differentiation was calculated according to Slatkin [13]. Hardy-Weinberg Equilibrium and Slatkin's genetic distance were calculated using Arlequin3.1 software (Excoffier et al. [14]). 


\section{Results and discussions}

\subsection{Species diversity}

Total population density and numbers of taxa ranged from 170 to 370 and 10 to 20, respectively. Nine taxa of Ephemeropteras, three taxa of Plecopteras, ten taxa of Trichopteras, six taxa of Coleoptera, Seven taxa of Dipteras and one taxon of Lepidoptera were found. Baetis spp and Cinygmula sp were dominant species from st. 1 to st. 5 and all stations, respectively. These 2 species occupied $36.8 \%$ of all samples. Shannon-Weiner's diversity indices ranged from 0.82 to 1.02 .

Figure 3 shows longitudinal variations of both Shannon-Weiner's diversity index $H^{\prime}$ and the number of taxa $\mathrm{S}$. Both parameters showed an increase in pattern at the outlet reaches compared to at the inlet reaches. These trends were more pronounced around Dai-ni dam, which the period of reconstructing slit facility was earlier than Dai-san dam. Species diversity is determined by two factors; carrying capacity depending on environmental condition and ease of ingression from outside at the station. The reasons for the increase in species diversities at the outlet reaches could be explained as: 1) new species could live in habitats at outlet reaches because the natural environmental condition of the area has recovered, 2) some species of benthic invertebrate were probably enabled to live in the downstream of the slit dams because flowing of organic matters (typical feed of benthic animals) and sediments due to slit have probably created conditions similar to natural river, 3) species which were absence in the downstream of the sabo dams could migrate from the upstream to the downstream after the reconstructions of the dams and the effect was accumulated as going to downstream. A decline in species diversity at st. 8 can be attributed to the riverbed compositions because the sediments of graves and stones were hardly found in the site. As st.8 is not close to Dai-ni dam (located in lowest downstream), the characteristic of the sediment pattern is not attributed to existence of sabo facilities.

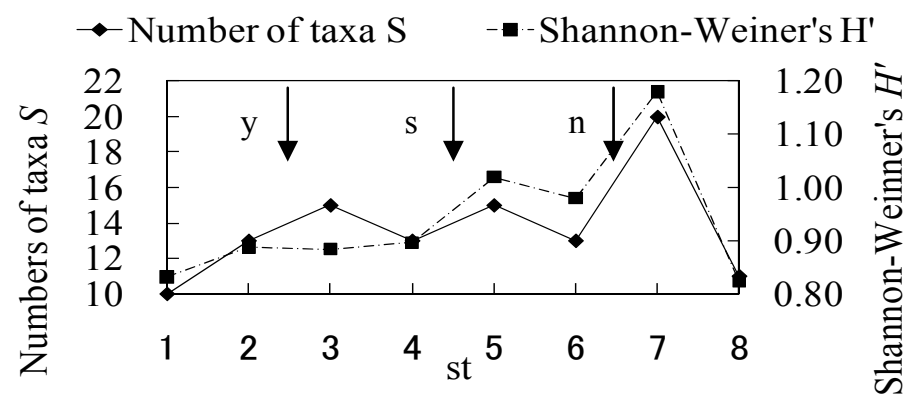

Figure 3: Longitudinal variations of both Shannon-Weiner's diversity index $\mathrm{H}$ ' and the number of taxa. he arrows show the location of sabo dam. The numbers attached to the arrows show the name of sabo dam. n: Dai-ni dam (slit type), s: Dai-san dam (slit type), y: Daiyon dam (unslit type). 


\subsection{Genetic diversity}

Table 1 shows number of sample individual $\mathrm{N}$, number of allele $\mathrm{A}$, mean heterozigosity $\mathrm{H}_{\mathrm{o}}$ and results of HWE test. Number of allele observed in 4 loci ranges from 4 to 10 . Mean heterozigosity ranges from 0.486 to 0.678 . According to the result of Watanabe and Omura [2], mean heterozigosity of S. marmorata at 24 sites in east Japan calculated by RAPD (Random Amplified Polymorphic

Table 1: Number of sample individual $\mathrm{N}$ which can be used to analyze, number of allele $\mathrm{A}$, mean heterozigosity $\mathrm{H}_{\mathrm{o}}$ and results of HWE test (*: $\mathrm{P}<0.05, * *: \mathrm{P}<0.01$, ns: not significant $(\mathrm{P} \geqq 0.05)$ ).

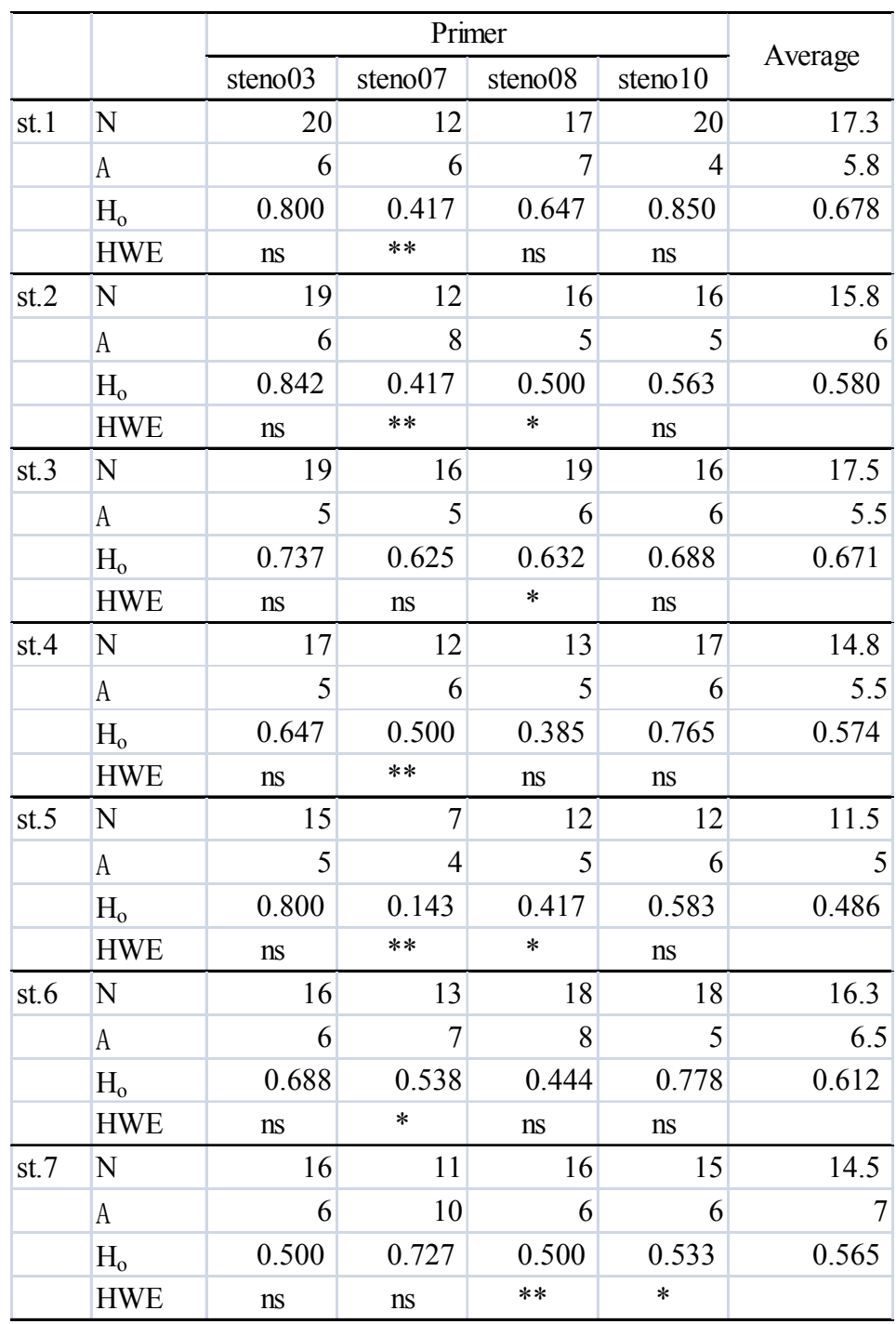


DNA) method ranged from 0.081 to 0.371 . Therefore, genetic diversity calculated by the microsatellite method shows higher value compared with other method. The mean heterozigosity of soybean genetic source in microsatellite $(=0.56-0.68)$ is higher than that in RAPD $(=0.31)$ (Powell et al. [15]). There were no significant difference among mean heterozigosity of each station (t-test, $\mathrm{P}>0.05)$. However, while the values are not significantly different, they decrease from st. 4 to st. $7\left(\mathrm{H}_{\mathrm{o}}=0.486-0.612\right)$ compared with st. $1\left(\mathrm{H}_{\mathrm{o}}=0.678\right)$ which has no effect from sabo dam (fig. 4).

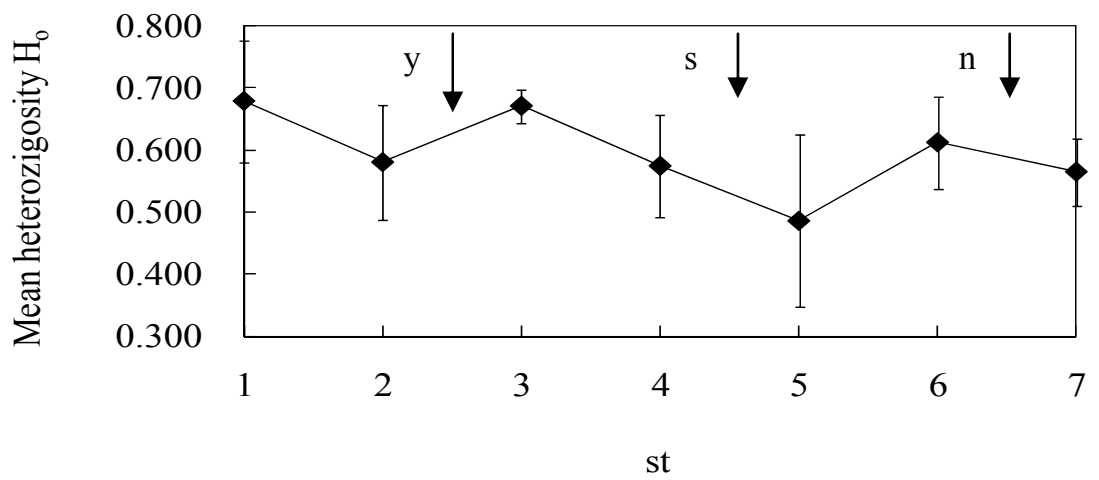

Figure 4: Longitudinal variation of heterozigosity $\mathrm{H}_{0}$. The bars indicate standard error of mean. The arrows are same as Figure 3.

\subsection{Genetic differentiation}

The magnitudes of genetic distance $\mathrm{D}$ which represents genetic difference between populations of 7 sites (st.1-st.7) range from 0 to 0.056 (Table 2). Therefore, genetic differentiation along the corridor is regarded as small. Figure 5 shows 3 correlations (a) difference between communities $\theta$ and geographical distance, (b) genetic distance D and geographical distance and (c) genetic distance $\mathrm{D}$ and difference between communities $\theta$. These estimations can be used (1) to compare the impacts of sabo dam on genetic or species level of macroinvertebrates, (2) to derive cause of the impacts, whether interruption of

Table 2: $\quad$ Slatkin's genetic distance D.

\begin{tabular}{|r|c|c|c|c|c|c|c|}
\hline & st.1 & st.2 & st.3 & st.4 & st.5 & st.6 & st.7 \\
\hline st.1 & - & & & & & & \\
\hline st.2 & 0.0000 & - & & & & & \\
\hline st.3 & 0.0000 & 0.0096 & - & & & & \\
\hline st.4 & 0.0000 & 0.0000 & 0.0000 & - & & & \\
\hline st.5 & 0.0077 & 0.0196 & 0.0191 & 0.0118 & - & & \\
\hline st.6 & 0.0000 & 0.0000 & 0.0000 & 0.0000 & 0.0558 & - & \\
\hline st.7 & 0.0215 & 0.0323 & 0.0000 & 0.0104 & 0.0434 & 0.0000 & - \\
\hline
\end{tabular}



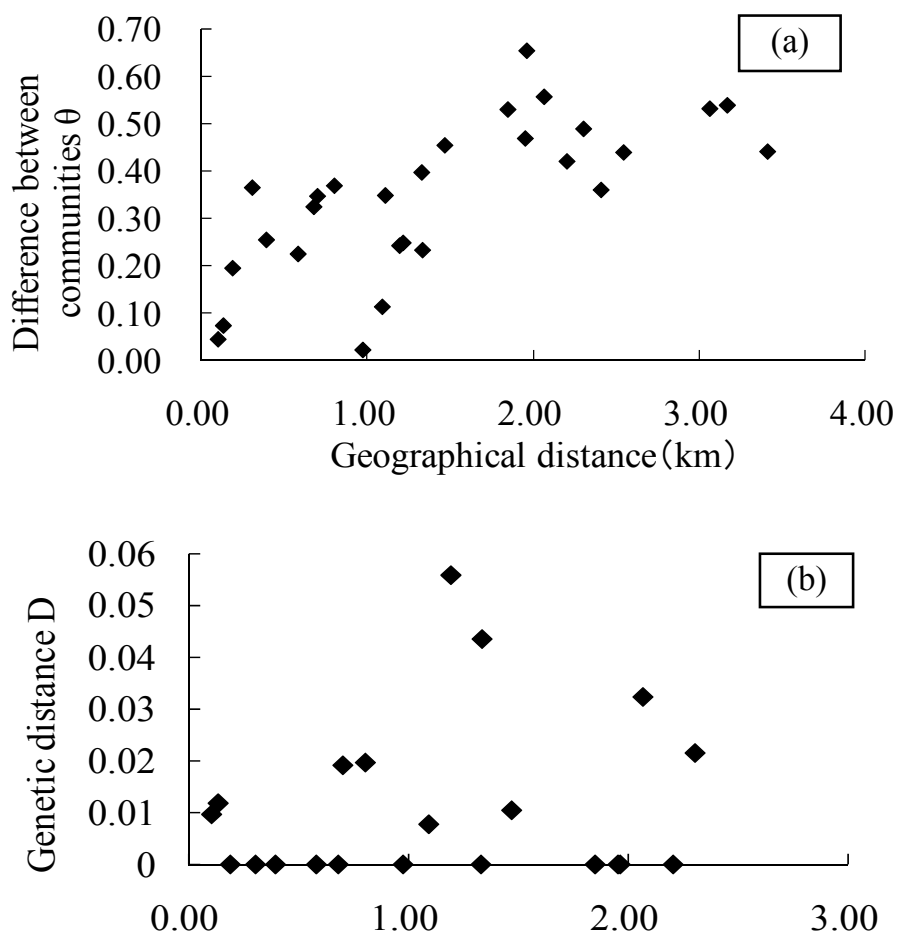

Geographical distance $(\mathrm{km})$

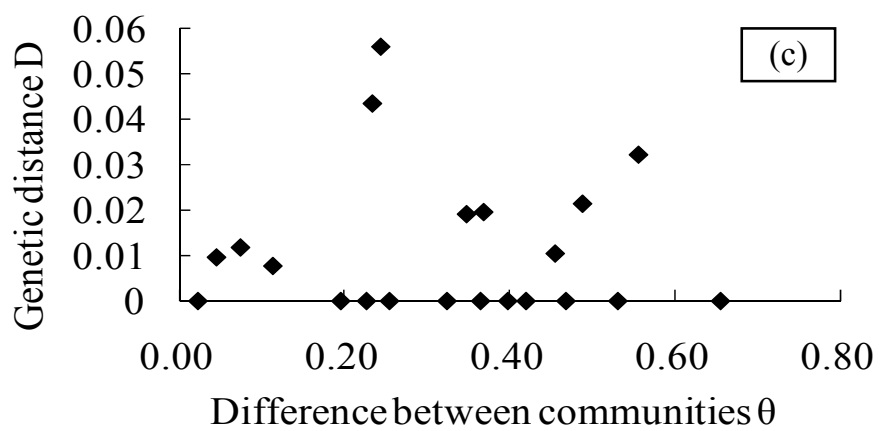

Figure 5: Correlations (a) difference between communities $\theta$ and geographical distance $\left(\mathrm{R}^{2}=0.51\right)$, (b) genetic distance $\mathrm{D}$ and geographical distance $\left(\mathrm{R}^{2}=0.02\right)$ and (c) genetic distance $\mathrm{D}$ and difference between communities $\theta\left(\mathrm{R}^{2}=0.01\right)$.

migrant or environmental alteration and (3) to evaluate how the effect spread longitudinally along the corridor. Sei et al. [16] found a correlation between genetic identity of benthic species Gamarus spp. and invertebrate community similarity. Moreover, they showed the species and genetic distance decreases as 
the geographical distance between communities separates. On the other hand, this study found a correlation of differences between communities $\theta$ and geographical distances $\left(\mathrm{R}^{2}=0.51\right)$. However, no significant correlations were found between genetic distances $\mathrm{D}$ and geographical distances $\left(\mathrm{R}^{2}=0.02\right)$, and genetic distances $\mathrm{D}$ and differences between communities $\theta\left(\mathrm{R}^{2}=0.01\right)$. It means as the geographical distance between communities separates, the intercommunion increases in species level, but not in genetic level. Therefore, it can be interpreted the relationship between communities $\theta$ and geographical distances is a result of community composition mutation attributed to adaptation to each environment (shown in Nukazawa et al. [17]). Following these findings, it can be concluded that 1) genetic structure of whole populations could be homogenized because the study corridor covers small area within $2.30 \mathrm{~km}$ (st.17), and 2) due to the small size of the sabo dams, they do not significantly contribute to gene flow of population. Moreover, according to the HWE tests, there was no significant difference $(\mathrm{P} \geqq 0.05)$ in 3 loci except steno07 which has not sample higher number of individual. For these reasons, the sabo dams have no significant effect on gene flow of population in the study area.

Table 3: $\quad$ Allele frequency in steno10.

\begin{tabular}{|c|r|r|r|r|r|r|r|}
\hline DNA fragment length & st.1 & st.2 & st.3 & st.4 & st.5 & st.6 & st.7 \\
\hline 104 & 0.00 & 0.00 & 0.00 & 0.00 & 0.00 & 0.00 & 0.07 \\
\hline 108 & 0.32 & 0.31 & 0.13 & 0.23 & 0.04 & 0.19 & 0.23 \\
\hline 110 & 0.00 & 0.00 & 0.00 & 0.00 & 0.04 & 0.00 & 0.03 \\
\hline 112 & 0.00 & 0.06 & 0.06 & 0.00 & 0.00 & 0.00 & 0.00 \\
\hline 114 & 0.30 & 0.41 & 0.31 & 0.12 & 0.67 & 0.44 & 0.17 \\
\hline 116 & 0.18 & 0.03 & 0.28 & 0.18 & 0.13 & 0.17 & 0.27 \\
\hline 118 & 0.20 & 0.19 & 0.19 & 0.03 & 0.04 & 0.03 & 0.00 \\
\hline 120 & 0.00 & 0.00 & 0.03 & 0.41 & 0.08 & 0.17 & 0.23 \\
\hline 122 & 0.00 & 0.00 & 0.00 & 0.03 & 0.00 & 0.00 & 0.00 \\
\hline
\end{tabular}

Table 3 shows allele frequencies in steno10 from st.1 to st.7. Allele frequencies of DNA fragment length $118 \mathrm{bp}$ (base pair) range from 0.19 to 0.20 in upstream sites (st.1-3) and from 0.03 to 0.04 in downstream sites (st.4-7). Moreover, allele frequencies of $120 \mathrm{bp}$ range from 0.00 to 0.03 in the upstream sites and from 0.08 to 0.41 in the downstream sites. These results indicate that genetic differentiation can be detected in the part of a locus between the upstream sites and downstream sites. Larva of $S$. marmorata constructs fixed type nest to feed particle organic matter from stream flow. Representative flow velocities of the upstream sites where 2 slit dams are located ranged from 0.84 to $0.98 \mathrm{~m} / \mathrm{sec}$. On the other hand, representative flow velocities of the downstream sites showed significantly lower values $(=0.51-0.71 \mathrm{~m} / \mathrm{sec}, \mathrm{P}<0.01$, t-test) compared with the upstream sites. These differences can be attributed to the shelving corridor caused by the construction of Dai-yon dam (unslit type). Therefore, genetic selections could occur in the part of a locus, and then it might 
lead populations to actualize the genetic differentiation because of the difference between the representative flow velocities.

\section{Conclusions}

Benthic communities and genetic diversity of $S$. marmorata were investigated to evaluate the impact of slit and unslit sabo dam in Oisawa River. Conclusions of the study are shown as follow.

(1) Shannon-Weiner's diversity index H' and the number of taxa shows increasing pattern at the outlet reaches compare to the inlet reaches. Reasons for increase in species diversities could be explained as; 1) new species could live in habitats at outlet reaches because the natural environmental condition of the area has recovered, 2) some species of benthic invertebrate might be enabled to live in the downstream of the slit dams because flowing organic matters (typical feed of benthic animals) and sediments due to slit may have created conditions similar to natural river, 3) species which were absence in downstream of sabo dam could migrate from upstream to the downstream after the reconstructions of the dam and the effect was accumulated as going to downstream.

(2) As the geographical distance between communities separates, the intercommunion increases in species level, but not in genetic level. High correlation of difference between communities and geographical distances $\left(\mathrm{R}^{2}=0.51\right)$ can be attributed to adaptation of invertebrates to each environment. As a conclusion, the sabo dams have no significant effect on gene flow of population in the study area.

(3) Two selective alleles which show clear genetic differentiation among three upstream sites (DNA fragment length 118bp) and four downstream sites (120bp) were found in a locus steno10. Therefore, genetic selections could occur in the part of a locus, and then it might lead populations to actualize the genetic differentiation because of the significant difference ( $\mathrm{t}$-test, $\mathrm{P}<0.05)$ of the representative flow velocities between the upstream and the downstream sites.

\section{Acknowledgements}

This research was partially supported by the Ministry of Education, Science, Sports and Culture, Grant-in-Aid for Scientific Research (B), 2010201322360192. This research was partially supported by the Ministry of Education, Science, Sports and Culture, Grant-in-Aid for Scientific Research (A), 2010-2013 (21254003)

\section{References}

[1] Gillenwater, D., Granataa and T., Zika U., GIS-based modeling of spawning habitat suitability for walleye in the Sandusky River, Ohio, and implications for dam removal and river restoration. Ecological Engineering 28, pp311-323, 2008. 
[2] Watanabe, K. and Omura, T., Relationship between reservoir size and genetic differentiation of the stream caddisfly Stenopsyche marmorata, Biological Conservation 136: pp203-211, 2007.

[3] Ohgushi, R., Suisei kontyu no sekai [The World of Aquatic Insects], Tokai University Press, 2004.

[4] Takemon, Y., Life-type concept and functional feeding groups of benthos communities as indicators of lotic ecosystem conditions, Japanese journal of Ecology 55, pp.189-197, 2005.

[5] Nunokawa, M. and Kikuchi, S., The density of benthic macroinvertebrate and abundance of benthic organic matter along the stream with check dams in southern Hokkaido, Japan, J. of Community Cooperative Research Center, Senshu Univ. 2, pp57-62, 2007.

[6] Kitamura, H and Ishimatsu, T., Field Observations of Aquatic Insect's Drift in a Mountain Stream with Sabo Facilities, Southern Kyusyu, Japan, Bulletin of Minamikyushu University 34(A), pp.19-31, 2004.

[7] Nishimura, N., Ecological studies on the net-spinning caddisfly, Stenopsyche Friseipennis Mclachlan II. Upstream-migration and determination of flight distance, Mushi 40, 39-46, 1967.

[8] Muller, K., The colonization cycle of freshwater insects, Oecologia 52, pp. 202-207, 1982.

[9] Kawai, T., Aquatic Insects of Japan: Manual with Keys and Illustration, Tokai University Press, 2005.

[10] Shannon, C.E., A mathematical theory of communication, Bell system technical journal 27(3), pp. 379-423, 1948.

[11] Pianka, E. R., The structure of lizard community, Annual Review of Ecology and Systematic, Vol.4, pp.53-74, 1973.

[12] Yaegashi, S., Watanabe, K., Omura, T., Isolation and Characterization of Ten Microsatellite Loci in the Caddisfly Stenopsyche marmorata (Trichoptera; Stenopsychidae), Molecular Ecology Resources, 2009.

[13] Slatkin, M., A measure of population subdivision based on microsatellite allele frequencies, Genetics 139, pp.457-462, 1995.

[14] Excoffier, L., Lavel, G., Schneider, S., Arlequin ver.3.1 : an integrated software package for population genetics data analysis, Evolutionary Bioinformatics Online 1, pp.47-50, 2005.

[15] Powell, W., Morgante, M., Andre, C., Hanafey, M., Vogel, J., Tingey, S. and Rafalski, A., The comparison of RFLP, RAPD, AFLP and SSR (microsatellite) markers for germplasm analysis, Molecular Breeding 2, pp.225-238, 1996.

[16] Sei, M., Lang, B.K., Berg, D.J., Genetic and community similarities are correlated in endemic-rich springs of the northern Chihuahuan Desert, Global Ecology and Biogeography 18, pp.192-201, 2009.

[17] Nukazawa, K., Kazama, S., Watanabe, K., Species diversity of benthic faunal communities along a mountain stream fragmented by slit and unslit sabo dams, Annual Journal of Hydraulic Engineering 54, JSCE, pp. 1285$1290,2010$. 